\title{
Potret Buram Politik Islam Indonesia
}

\section{Zaki}

\author{
Fakultas Ushuluddindan Studi Agama UIN Mataram \\ Email:amakikaz02@gmail.com
}

\begin{abstract}
Abstrak: Agama dan politik memiliki relasi yang sangatlah unik, dan menarik. Keduanya kadang bermula dari perseteruan dan bertepi dengan kemesraan. Artikel ini membahas tentang potret politik Islam di Indonesia. Temuan artikel menunjukkan bahwa Indonesia hanyalah sekelumit contoh faktaneka hostoris betapa agama $t$ elah melakukan fungsi kritisnya sebagai medium kritik sosial sebuah masyarakat sekaligus sarana perubahan politik sebuah tatanan kekuasaan. Bukan hanya agama, politik juga sering melawan, mengintimidasi, dan menghancurkan agama. Diskriminasi ulama dan pemuka agama yang ghalib terjadi akhir-akhir ini di setiap jengkal tanah dalam buaian ibu pertiwi adalah faktaneka historis yang tak terbantahkan. Dengan kata lain, hubungan sekaligus nasib agama dan politik akan ditentukan oleh otoritas mana yang paling kuat dan dominan dari keduanya serta bagaimana karakter para elit politik dan elit agama yang kebetulan berkuasa. Jika politik menjadi ,superordinat', maka agama akan berpotensi menjadi, subordinat'. Begitu pula sebaliknya.
\end{abstract}

Kata Kunci: Politik Islam, Indonesia, relasi agama dan politik

\begin{abstract}
Religion and political relations are very unique and interesting. Both of them sometimes originated from feud and edge with intimacy. This article discusses the portrait of Islamic politics in Indonesia. The article founds of indicating that Indonesia is only a small sample of various histories how religion has performed its critical function as a medium of social criticism of society as well as a means of the political change in a power order. It is not only religion that opposes politics. Politics also often resist, intimidate and destroy religion. The discrimination of clerics and religious leaders that have occurred recently in every Indonesian motherland is an undeniable historical fact. In other words, the relationship, as well as the fate of religion and politics, will be determined by which authority is the most powerful and dominant of the two and how the character of the political elite and religious elite who happen to be in power. If politics becomes "superordinate", then religion will potentially become "subordinate", and vice versa.
\end{abstract}

Keywords: Politics of Islam, Indonesia, religious and political relations 


\section{Pendahuluan}

Relasi antara agama dan politik sangatlah unik, menarik, dan hampir lucu. Keduanya kadang bermula dari perseteruan dan bertepi dengan kemesraan. Sejarah jelas telah mencatat dengan tinta emasnya bahwa tokoh, komunitas, dan institusi keagamaan bisa berperan menjadi penjaga moral masyarakat serta pengkritik kekuasaan yang garang. Pula, agama bisa menjadi sumber energi luar biasa untuk melakukan perlawanan terhadap rezim korup dan despotik. Tunjuk misal, sejarah gerakan Gereja Katolik di Amerika Latin, ${ }^{1}$ Black Chruches di Amerika Serikat, Sufi Sanusiyah di Lybia, atau Tarekat Qadiriyah-Naqsabandiyah di Banten, ${ }^{2}$ Indonesia, hanyalah sekelumit contoh faktaneka hostoris betapa agama telah melakukan fungsi kritisnya sebagai medium kritik sosial sebuah masyarakat sekaligus sarana perubahan politik sebuah tatanan kekuasaan.

Penting untuk dicatat, bukan hanya agama yang melakukan perlawanan terhadap politik. Politik juga sering melawan, mengintimidasi, dan menghancurkan agama. Diskriminasi ulama dan pemuka agama yang ghalib terjadi akhir-akhir ini di setiap jengkal tanah dalam buaian ibu pertiwi adalah faktaneka historis

${ }^{1}$ Sebuah gerakan yang dikomandoi oleh Gustavo Gutiérre z, seorang imam Dominikan yang me ngajak Gereja Katolik Amerika Latin untuk hadir dan berjuang bersama orang miskin untuk melawan pemerintahan yang korup dan despotik. Lihat Che n Martin, Teologi Gustavo Gutiérrez: Refleksi dari Praksis Kaum Miskin, (Yogyakarta: Kanisius, 2002), 55.

2 Selain pe ne kanannya terhadap syari'ah, ciri yang sangat me nonjol dalam tarekat Naqsabandiyah adalah upaya yang serius dalam mempe ngaruhi kehidupan dan pemikiran golongan pe nguasa serta me nde katkan Negara kepada agama. Tarekat ini tidak me nganut kebijaksanaan isolasi diri dalam me nghadapi pemerintah (kolonial Belanda) yang sedang berkuasa. Sebaliknya ia melancarkan konfrontasi dengan berbagai kekuatan politik agar dapat mengubah pandangan mereka. Lihat, Wiwi Siti Sajaroh, ,Tarekat Naqsabandiyah, Me njalin Hubungan Harmonis de ngan Kalangan Pe nguasa', dalam Sri Mulyati, dkk., Mengenal dan Memahami TarekatTarekat Muktabarah di Indonesia, (Jakarta : Ke ncana, 2006), 91. 
yang tak terbantahkan. Dengan kata lain, hubungan sekaligus nasib agama dan politik akan ditentukan oleh otoritas mana yang paling kuat dan dominan dari keduanya serta bagaimana watak dan karakter para elit politik dan elit agama yang kebetulan berkuasa. Jika politik menjadi ,superordinat', maka agama akan berpotensi menjadi, subordinat'. Begitu pula sebaliknya.

Tetapi di sisi lain, agama juga bisa berfungsi sebagai ,stempel' atau legitimator politik-kekuasaan sejak zaman "baheula" hingga pada masa keinian. Di sejumlah negara, dewasa ini agama-politik banyak melakukan ,perkawinan' dan menjalin hubungan ,simbiosisme mutualisme': politik memberi garansi proteksi keamanan masyarakat agama, sementara agama memberi ,legitimasi teologis' untuk melanggengkan kekuasaan politik. Dalam konteks ini, secara teoretis hubungan agama dan politik adalah sejajar (koordinat), bukan saling mendominasi dan menguasai tetapi saling melengkapi dan menguntungkan satu sama lain. Meskipun dalam prakteknya tentu saja tetap terjadi ,perselingkuhan' sana-sini dimana agama atau politik mencoba ,main mata' dan ,berselingkuh' dengan pihak lain di luar ,komunitas agama' (misalnya kelompok adat, kaum pebisnis, sekuler-ateis, dan lain sebagainya), atau bahkan secara diam-diam saling menjegal dan mendelegitimasi otoritas masing-masing.

\section{Menggali Sejarah Menimba Ibrah}

Faktaneka sejarah mengeksplanasikan betapa dinamis dan fleksibelnya relasi agama dan politik di Indonesia. Dulu pada masa kolonial, agama berperan ganda: sebagai legitimasi kolonialisme sekaligus kritik sosial. Banyak tokoh agama, Muslim khususnya, 
yang bekerja dengan pemerintah kolonial. ${ }^{3}$ Tetapi pada saat yang bersamaan juga banyak di antara mereka yang menjadi pengkritik dan pemberontak terhadap eksistensi kolonial. ${ }^{4}$ Potret yang sama juga berulang pada zaman Orde Lama. Presiden Soekarno di satu sisi mengakomodasi tokoh-tokoh Muslim (khususnya dari kalangan Nahdlatul Ulama), ${ }^{5}$ tetapi pada waktu yang bersamaan melibas tokohtokoh Muslim lain (khususnya dari Masyumi) yang kontra dengan kekuasaanya.

Pada masa revolusi, relasi harmoni antara Soekarno-Masyumi berperan signifikan dalam mewujudkan pemerintahan di Indonesia. Masyumi sebagai sebuah partai, memiliki kontribusi signifikan dalam pengukuhan identitas Islam di panggung politik Indosesia. Eksistensinya mampu mengikat erat dan berjalin berkelindan

${ }^{3}$ Kelompok ini berasal dari kalangan bangsawan, al-Mulk at-Thawaif dan Rayes de Tipes yang sedari awal me ngambil posisi insider. Dalam konte ks sikap keberagamaan, mayoritas di antara mereka pe nghayat Islam sinkkre tik kejawenabangan.

${ }_{4}^{4}$ Ane ka perlawanan kaum Muslim yang diaktori oleh para ulama terhadap eksiste nsi kolonialisme Belanda antara lain Perang Paderi (1821-1827), Perang Dipone goro (1825-1830) dan Perang Aceh (1875-1905). Re nte tan perlawanan ini dipantik oleh seruan jihad dalam doktrin al-Din al-Islam dan kebijakan politik kolonialisme Belanda yang kental dengan nuansa diskriminatif terhadap umat Islam. Lihat Aqib Sumito, Politik Islam Hindia Belanda, (Jakarta : LP3ES, 2006), 12; Sartono Kartodirjo, Pengantar Sejarah Indonesia Baru 1500-1900, Dari Emporium sampai Imperium, cet. XVII (Jakarta : Gramedia Utama, 2009), 294.

${ }_{5}^{5}$ Titik temu antara Soekarno de ngan NU, tidak disimbolkan secara fisikli sebagaimana pledoi Mahfud MD di acara ILC \#AntaraMaharDanPHP 14-08-2018, dalam rangka me njawab serangan Aqil Sirajd yang me nuduhnya bukan kader NU pada moment krusial konte stasi politik. Mahfud MD berhujjah, me njadi kader NU tidak harus me ngikuti pelatihan organisasi dan tertera me njadi pengurus organisasi yang dilegalkan dengan surat keputusan. Menurutnya, menjadi NU tulen itu apabila ide dan gagasan NU te ntang nilai-nilai kebangsaan, nasionalisme, kebhine kaan, toleransi dan pluralitas tampak dalam merawat keutuhan NKRI. 'Alakullihal, pada tataran inilah Soekarno dan NU me ne mukan kalimatun sawa yang simbiosisme mutualisme, tanpa pernah namanya tercatat dalam kepe ngurusan NU. 
dengan seluruh capital social (modal sosial) ${ }^{6}$ yang dimiliki oleh umat Islam sebagai umat mayoritas di Indonesia. Modal sosial yang dimiliki umat Islam, yang direfresentasikan oleh Masyumi, bukan hanya sekumpulan institusi yang menopang (NU, Muhammadiyah, Perti, PSII dan lainnya), tetapi lebih jauh-dengan social trust dan social norm- merupakan perekat yang menggerakkan mereka bersama-sama. Melalui aneka ikatan horizontal, berperan dan karenannya dibutuhkan untuk memberi komunitas suatu sense identitas dan tujuan bersama. Secara keseluruhan, modal sosial merangkai akumulasi dari berbagai aset sosial, psikologi, kultur, kognitif, institusional dan aset-aset yang dapat meningkatkan jumlah (atau probabilitas) perilaku kooperatif yang saling menguntungkan, antara Soekarno di satu pihak dan Masyumi di pihak yanglain.

Modal sosial memang potensial memudahkan koordinasi dan relasi kerja sama, tetapi ia juga memiliki suatu ,downside', semacam sisi gelap dalam penampakannya. Tokoh-tokoh Masyumi -Natsir, misalnya- menghendaki ideologi Islam sebagai dasar berbangsa dan bernegara. Baginya, Islam bukan semata-mata religi, yaitu agama dalam pengertian ruhaniah saja. Islam mengatur hubungan antara manusia dengan Allah SWT, dan antar sesama manusia. Islam merupakan pedoman dan falsafah hidup yang tidak mengenal

${ }^{6}$ Modal sosial (social capital) me nunjuk pada institusi-institusi, hubunganhubungan, dan norma -norma yang me ne ntukan kualitas dan kuantitas inte raksi sosial masyarakat. Dalam dinamika inte raksi tersebut, ia berjalin berkelindan dengan adanya sikap saling percaya (trust) dan norma -norma sosial yang berlaku, serta jaringan sosial yang efektif dimana dengan itu semua anggota masyarakat berupaya me ngatasi berbagai problem secara bersama dalam suatu pola hubungan timbal balik, se hingga dapatmeningkatkan efesiensi masyarakat dengan cara memfasilitasi tindakan-tindakan terkoordinasi. Lihat Zaki dkk., ,Kohe sivitas Berbasis Modal Sosial, Belajar dari Kaum Wetu Telu', dalam Jurnal Istiqra' : Penelitian Islam Indonesia, Vol. 05, No. 01, 2006 : 159-191. 
pemisahan antara agama dari politik. Oleh sebab itu, dalam masa revolusi umat Islam di Indonesia bukan saja dijiwai oleh aspirasi nasional, melainkan juga oleh aspirasi Islam. ${ }^{7}$

Perdebatan dan konforntasi Masyumi dan Soekarno menyangkut masalah ideologi dalam berbangsa dan bernegara terus berlanjut. Soekarno dalam pidatonya di Amuntai, Kalimantan Selatan tanggal 27 Januari 1953, kembali memperteguh komitmen kebangsaannya dengan menginginkan negara nasional yang berideologi Pancasila dan bukan negara berdasarkan ideologi Islam. Pernyataan Sukarno itu mendapat tanggapan berbagai kalangan, khususnya tokoh-tokoh Masyumi.

Puncak perdebatan dan konfrontasi Soekarno dengan Masyumi bertepi ketika Soekarno mengeluarkan ,Dekrit ' dan diberlakukannya ,Demokrasi Terpimpin' tahun 1959. Keluarnya Dekrit tersebut semakin memperkuat dan memperbesar kekuasaan Soekarno di satu pihak, sementara di pihak lain semakin melemahkan posisi dan peran Masyumi sebagai partai politik. Bukan hanya peran politik Masyumi semakin merosot, tetapi eksistensinya pun diamputasi dan dikebumikan melalui surat keputusan nomor 200 tahun 1960. ${ }^{8}$ Menghadapi keputusan tersebut, Masyumi mengabil dua opsi cerdas. Pertama, pimpinan Masyumi menyatakan diri bubar melalui suratnya nomor 1801 BNI-25/60 tanggal 13 September 1960. Pembubaran diri ini dimaksudkan untuk menghindari cap sebagai partai terlarang, dan korban yang tidak perlu, baik terhadap anggota Masyumi dan keluarganya, maupun asetaset Masyumi. Kedua, menggugat Soekarno di pengadilan.

7 Insan Fahmi Siregar, Partai Masyumi dalam Dinamika Demokrasi Indonesia, (Se marang : Widya Karya, 2014), 54.

${ }^{8}$ Dilear Noer, Partai Islam di Pentas Nasional 1945-1960, (Bandung : Mizan, 2000), 216. 
Usaha Masyumi mencari keadilan di pengadilan menemui jalan buntu. Kebuntuan itu terjadi karena adanya intervensi S oekarno terhadap proses pengadilan. ${ }^{9}$

Setali tiga uang, potret umat Islam pada era Orde Baru dalam konteks agama, politik dan kekuasaan pun tidak lebih baik dari masamasa sebelumnya. Suara-suara yang ingin menegakkan Syari'at Islam atau Islam sebagai dasar negara nyaris tak terdengar. Boleh jadi karena intervensi negara yang terlalu kuat terhadap gerak-gerik warganya termasuk ormas, membuat semuanya menjadi diam dan tiarap, seolah ada kesimpulan bahwa berbeda dengan mainstrem negara adalah berbahaya. Bukan itu saja, melalui Undang- Undang Nomor 8 tahun 1985 pemerintah mulai menerapkan mono-loyalitas, mengharuskan seluruh organisasi kepemudaan, kemasyarakatan dan keagamaan berasaskan Pancasila, sebagai satu-satunya asas. ${ }^{10}$ Kita menyebutnya asas tunggal. Dengan peraturan baru itu setiap perserikatan yang tidak berasaskan Pancasila dianggap bertentangan dengan negara, dan nasibnya pun kita sudah tahu: dibubarkan dan dikebumikan.

Kebijakan refresif rezim Orde Baru, memaksa kecenderungan gerak politik Islam, bergeser ke arah yang lebih netral, dari minoritas politik ke mayoritas kultural. Mayoritas aspirasi umat, tidak memandang aktifitas politik sebagai satu-satunya wadah perjuangan dalam rangka berkhidmat pada Islam. Gerakan Islam sedang melangkah ke arah spektrum baru yang lebih dominan bersifat kultural ketimbang politik. Pada era ini Islam sebagai gerakan kultural dapat dirumuskan dalam tiga sub gerakan, yakni:

${ }^{9}$ MC. Rickle fs, Sejarah Indonesia Modern, (Yogyakarta : Gadjah Mada Unive rsity Press, 1991), 176. 67.

${ }^{10}$ Ali F, Islam, Pancasila dan Pergulatan Politik, (Jakarta : Pustaka Antara, 2004), 
intelektual, etik dan estetik. ${ }^{11}$ Fenomena inilah yang dipandang sebagai format baru gerakan Islam dalam penghadapannya dengan konteks kesejahteraan masyarakat Indonesia dalam arti yang umum dan tentu saja dalam kurun waktu yang lebih mutakhir.

Diskursus gerakan Islam kultural, ditandai oleh bangkitnya kepemimpinan intelektual Muslim yang menyoal isu-isu sosial, ekonomi, intelektual dan estetika. Dus, melemahnya sikap-sikap sektarian dan memudarnya konsep umat yang diikat oleh organisasi massa Islam atau partai politik Islam yang eksklusif. Inilah yang oleh Donald K. Emmerson disebut sebagai diskursus Islam yang tengah menegaskan dimensi kulturalnya, jika bukan sama sekali apolitis.12 Faktor dominan yang mempengaruhi kondisi ini adalah perubahan struktural di dalam kehidupan politik dan sosio-ekonomi sebagai akibat kebijakan yang dijalankan Orde Baru. Situasi ini menciptakan ketegangan ideologis antara Islam dengan Negara yang berbuntut kekalahan umat Islam sedikitnya dalam konstitusi, pemilihan umum, fisik, birokrasi dan simbol. ${ }^{13}$

Setelah Soeharto lengser dan Orde Baru tamat, Indonesia memasuki fase baru dalam kehidupan berbangsa dan bernegara yang disebut era reformasi. Keran kebebasan berekspresi dan berserikat kembali terbuka lebar di era ,canggung' ini. Bagi komunitas Muslim, momentum ini sekaligus membangkitkan kembali ghirrahnya untuk menceburkan diri dalam lembah

${ }^{11}$ Kuntowijoyo, ,Agama Berdime nsi Banyak, Politik Berdime nsi Tunggal', dalam Abu Zahrah (e d.), Politik Demi Tuhan, (Bandung; Pustaka Hidayah, 1999), h. 121.

${ }_{12}$ Donald K. Emerson, Indonesia Beyond Soeharto, (Jakarta : Gramedia Pustaka Utama, 2001), 211.

${ }^{13}$ Bachtiar Effe ndy, Islam dan Negara : Transformasi Pemikiran dan Praktek Politik Islam di Indonesia, (Jakarta : Paramadina), 78. 
kekuasaan politik. ${ }^{14}$ Ada dua hal yang dapat disimak mengapa partaipartai Islam muncul pada awal orde reformasi: Pertama, pada awal pemerintahan orde baru, Soeharto sadar terdapat dua resistensi politik yang bakal dihadapi, yaitu komunisme dan Islam. Untuk menghadapi komunis, Soeharto bersinergi dengan kelompok Islam. Pada sisi lain, setelah berhasil membasmi komunis sampai ke akar- akarnya, Soeharto mulai mengawasi dan memata-matai umat Islam yang berseberangan dengan kebijakan politiknya dengan menempatkan aparat intelejen. Dengan landasan ini, orde baru secara sempurna menerapkan strategi politik Snouck Hurgronje terhadap Muslim. Muslim dipandang sebagai kelompok kiri yang berjuang melawan represi politik, serta memperjuangkan persamaan hak dan kewajiban bagi seluruh rakyat Indonesia, baik dalam perspektif politik, ekonomi, dan budaya. ${ }^{15}$

Strategi politik kedua adalah menyederhanakan partai politik menjadi tiga partai, Golkar, PDI, dan PPP. Partai politik di luar mainstream, baik PDI maupun PPP didesain agar tidak dapat menang dalam pemilihan umum. Desain ini mengingatkan strategi politik

14 Pada awal re formasi (pe milu 1999) terdapat 20 partai politik berasaskan Islam dan/atau berbasis massa Islam yaitu: [a] PKU (Partai Kebangkitan Umat); [b] PNU (Partai Nahdatul Umat); [c] SUNNI; [d] PKB (Partai Kebangkitan Bangsa); [e ] PAN (Parai Amanat Nasional); [f] PBR (Partai Bintang Re formasi); [g] PBB (Partai Bulan Bintang); [h] PK (Partai Keadilan); [i] PSII (Partai Syarikat Islam Indone sia); [j] PUI (Partai Umat Islam); [k] PMB (Partai Masyumi Baru; [1] PKMI (Partai Kebangkitan Muslim Indone sia); [m] PKU (Partai Kebangkitan Umat); [n] PPP (Partai Persatuan Pembangunan); [o] PSII 1905 (Partai Syarikat Islam Indone sia 1905); [p] PAY (Partai Abul Yatama); [q] PID (Partai Islam Demokrat); [r) PKP (Partai Keadilan dan Persatuan); [s] Partai Politik Islam Masyumi; [t] Partai Persatuan. Dari 20 partai ini hanya tiga partai yang lolos electoral thershold 2,5\% yaitu PPP: $10.71 \%$, PAN: $7.12 \%$, dan PKB: 12.61\%. Lihat Syarifuddin Jurdi, Pemikiran Politik Islam Indonesia: Pertautan Negara, Khilafah, Masyarakat Madani, dan Demokrasi, (Yogyakarta: Pustaka Pelajar, 2008), 181.

${ }^{15}$ Kazuo Shimogaki, Kiri Islam: Antara Modernisme dan Post Modernisme, Telaah Kritis Pemikiran Hassan Hanafi, (Yogyakarta: LKiS, 1993), 6. 
Belanda yang disebut beamtenstaat untuk domestikasi partai politik, dan menciptakan floating mass (masa mengambang) sehingga akan mendapat keunggulan suara dalam pemilu. Apabila di suatu daerah salah satu partai politik (PDI dan PPP) itu menang, maka pembangunan di daerah itu bakal dihambat.

Empat kali pemilihan umum, memilih anggota legislatif maupun presiden dan wakil presiden, sudah diselenggarakan pasca reformasi, yakni pada tahun 1999, 2004, 2009, dan 2014. Dalam empat kali pemilu itu, partai politik Islam mengalami pasang surut, dan angka perolehan partai politik Islam dalam pemilihan umum relatif kecil, yakni di bawah 10\%. Sementara itu mayoritas pemilih beragama Islam adalah $88 \%$ dari populasi penduduk Indonesia yang berjumlah 240 juta jiwa. Fenomena ini bermakna bahwa suara partai politik Islam tidak mencerminkan kekuatan pemilih mayoritas. ${ }^{16}$ Problem utamanya adalah elit politik sangat lemah dalam mengelola civic culture (tradisi budaya politik demokrasi) dan political engagement (perasaan dan ketertarikan pemilih terhadap partai politik Islam) terhadap basis massa partai politik Islam. Rendahnya tingkat kelola dari elit politik terhadap dua aspek di atas berdampak pada rendahnya political interest massa pemilih partai politik Islam.

Faktor psikologis sangat dominan terhadap partisipasi pemilih. Civic culture dan political engagement yang melekat pada partai politik dapat memicu rasa tertarik terhadap partai politik. Pemilih selanjutnya akan mendiskusikan perihal partai itu, termasuk diskusi politik 'siapa saja elit politik' yang dicalonkan menjadi anggota legislatif. Diskusi itu memberi informasi mengenai keyakinan individu terhadap partai politik Islam pilihan. Seringkali

16 Saiful Mujani, R. William Liddle \& Kuskridho Ambardi, Kuasa Rakyat: Analisis tentang Perilaku Memilih dalam Pemilihan Legislatif dan Presiden Indonesia Pasca Orde Baru, (Jakarta: Mizan Publika, 2012), 371. 
hasil diskusi politik itu justru menimbulkan sisi negatif, yakni individu bermigrasi kepada partai politik non Islam. Problem perpindahan partisipasi politik terhadap partai non Islam, tentu banyak faktornya. Indikasi perpindahan di samping telah disebutkan di atas, juga karena persoalan sifat toleransi partai politik terhadap penghayat agama yang berbeda dalam kehidupan masyarakat.

Selain faktor psikologis, setidaknya ada tiga isu dalam globalisasi yang berhubungan dengan partai politik Islam, yakni: [1] Isu borderless, dunia tanpa batas, yakni berkembangnya relasi-relasi antar individu baik dalam konteks lintas batas negara, bangsa, suku, ras, maupun agama. Dengan adanya sifat borderless itu berimplikasi pada tumbuhnya teknologi informasi dan komunikasi. [2] Tumbuhnya diaspora sebagai akibat borderless itu, sehingga perlu melakukan dekonstruksi untuk memberi pengakuan terhadap identitas budaya masyarakat. Pengakuan identitas menjadi sangat penting, bahkan dalam konteks ini negara maupun partai politik tidak dapat menghegemoni identitas. Penafsiran yang perlu dikemukakan dalam konteks partai politik adalah ,stigma politik' negatif maupun positif dapat meningkatkan ataupun menurunkan jumlah perolehan suara dari kelompok basis massa Islam. Dan [3] Globalisasi memacu timbulnya konflik akibat proses dekonstruksi yang terhambat. Perdebatan mengenai ortodoksi dan sinkretik, modern dan tradisional, liberal dan konservatif, dan radikal dan harmoni merupakan fenomena psikologis yang dapat mempengaruhi perolehan suara pemilih. ${ }^{17}$

${ }^{17}$ Kamaruzzaman Bustaman-Ahmad, Wajah Baru Islam di Indonesia (Yogyakarta: UII Press, 2004), 178. 


\section{Awal Dari Sebuah Akhir}

Menghadapi pemilu legislatif dan pilpres 2019, Komisi Pemilihan Umum telah menetapkan enam belas partai politik peserta pemilu. Dari enam belas tersebut, lima di antaranya tergolong partai Islam atau berbasis massa Islam antara lain: PPP, PAN, PKB, PKS dan PBB. Kelima partai ini, secara moral dan etika dilandasi nilai Islam, sehingga politik bisa menjadi alat perjuangan bagi mewujudkan kepentingan umat. Wajah politik yang sering kali diidentikkan kotor dan licik akan menjadi lebih santun karena moral agama menjadi panduan. Ini tantangan bagi politisi Muslim, yakni bagaimana mengaplikasikan akhlak mulia dalam kehidupan berpolitik dan berdemokrasi, sehingga ada dampak positif pada setiap keputusan dan kebijakan politiknya. Untuk itu, partai berbasis massa Islam dituntut mampu menjawab realitas sosial masyarakat. Termasuk kemampuannya dalam menginternalisasikan nilai Islam dalam kehidupan bermasyarakat dan bernegara.

Konstruksi ideologis (Islam), jika tidak diimbangi kepekaan terhadap isu sosial akan menyebabkan partai Islam kehilangan basis massanya. Partai Islam juga harus mentransformasikan kekuasaan politik dengan bersandar pada demokrasi dan praktik politik kontemporer. Karena itu, partai Islam harus sepenuhnya berpijak pada data sosial yang ada seperti tidak hanya terpaku pada simbolsimbol agama dalam upaya menarik massanya, tetapi juga pada persoalan konkret serta kebutuhan riil masyarakat. Secara moral dan etika, partai Islam dituntut lebih memperhatikan aspirasi umat. Isu utama yang menjadi perhatian umat adalah korupsi dan kesejahteraan ekonomi, seperti pengangguran dan keterjangkauan harga sehari-hari. Sayangnya, isu utama seperti korupsi masih membelit semua partai politik, tak terkecuali partai berbasis massa 
Islam. Hal ini menyebabkan tidak ada diferensiasi antara partai berbasis agama dan non-agama.

Kondisi politik umat Islam di negara kita memang heterogen, yang melahirkan polarisasi dalam aspirasi politik. Maka itu, tak mengherankan jika partai Islam sulit bersatu dalam memunculkan satu tokoh Islam menjadi pemimpin di kalangan mereka. Meski demikian, posisi umat Islam yang mayoritas tetap strategis dan signifikan. Kenyataan ini menjadikan banyak kekuatan sosial dan politik berlomba meraih dukungan umat. Harus diakui pula, beberapa survei menunjukkan kepercayaan rakyat terhadap partai menurun. Ini artinya, ada degradasi peran partai sebagai infrastruktur politik dalam menjembatani aspirasi rakyat. Salah satunya adalah moral politik saat ini yang cenderung koruptif bahkan kadang manipulatif terkait politik uang.

Dengan kondisi seperti ini, seharusnya partai berbasis massa Islam menempatkan diri sebagai partai bersih yang peduli rakyat. Sayangnya, yang terjadi justru ada penurunan yang dirasakan oleh partai berbasis massa Islam. Di sejumlah survei, partai-partai berbasis massa Islam berada di level menengah ke bawah. Ini tentu tantangan besar. Jika partai berbasis massa Islam mampu menghadirkan jalan kesejukan dan etika Islam dalam politik, bukan tidak mungkin mereka menjadi pilihan rakyat. Namun sebaliknya, jika partai Islam ikut terjebak menjadi bagian dari moralitas dan etika politik pragmatis (koruptif), penilaian miring dan hukuman pemilih terhadap partai Islam lebih keras. Sebab, partai-partai itu membawa simbol agama dalam ruang politik. Dan sangat mungkin inilah awal dari sebuah akhir, dimana partai politik Islam masuk dalam lipatan sejarah. Allahuaklam bishawab. 


\section{Daftar Rujukan}

Ahmad, Kamaruzzaman Bustaman, Wajah Baru Islam di Indonesia, Yogyakarta: UII Press, 2004.

Ali F, Islam, Pancasila dan Pergulatan Politik, Jakarta : Pustaka Antara, 2004.

Effendy, Bachtiar, Islam dan Negara : Transformasi Pemikiran dan

Praktek Politik Islam di Indonesia, Jakarta : Paramadina, 2014.

Emerson, Donald K., Indonesia Beyond Soeharto, Jakarta :Gramedia Pustaka Utama, 2001.

Fahmi Siregar Isan, Partai Masyumi dalam Dinamika Demokrasi Indonesia, Semarang : Widya Karya, 2014.

Jurdi, Syarifuddin, Pemikiran Politik Islam Indonesia: Pertautan Negara, Khilafah, Masyarakat Madani, dan Demokrasi, Yogyakarta: Pustaka Pelajar, 2008.

Kartodirjo, Sartono, Pengantar Sejarah Indonesia Baru 1500-1900, Dari

Emporium sampai Imperium, cet. XVII, Jakarta : Gramedia Utama, 2009.

Kuntowijoyo, ,Agama Berdimensi Banyak, Politik Berdimensi Tunggal', dalam Abu Zahrah (ed.), Politik Demi Tuhan, Bandung; Pustaka Hidayah, 1999.

Martin, Chen Martin, Teologi Gustavo Gutiérrez: Refleksi dari Praksis Kaum Miskin, Yogyakarta: Kanisius, 2002.

MC. Ricklefs, MC., Sejarah Indonesia Modern, Yogyakarta : Gadjah Mada University Press, 1991.

Mujani, Saiful Mujani, R. William Liddle \& Kuskridho Ambardi, Kuasa Rakyat: Analisis tentang Perilaku Memilih dalam Pemilihan Legislatif dan Presiden Indonesia Pasca-Orde Baru, Jakarta: Mizan Publika, 2012. 
Noer, Dilear Noer, Partai Islam di Pentas Nasional 1945-1960, Bandung : Mizan, 2000.

Sajaroh, Wiwik Siti, ,Tarekat Naqsabandiyah, Menjalin Hubungan Harmonis dengan Kalangan Penguasa', dalam Sri Mulyati, dkk., Mengenal dan Memahami Tarekat-Tarekat Muktabarah di Indonesia, Jakarta : Kencana, 2006.

Shimogaki, Kazuo, Kiri Islam: Antara Modernisme dan Post Modernisme, Telaah Kritis Pemikiran Hassan Hanafi, Yogyakarta: LKiS, 1993.

Sumanto, Sumito, Politik Islam Hindia Belanda, Jakarta : LP3ES, 2006. Zaki dkk., ,Kohesivitas Berbasis Modal Sosial, Belajar dari Kaum Wetu Telu', dalam Jurnal Istigra' : Penelitian Islam Indonesia, Vol. 05, No. 01, 2006 